\title{
Legal Responses to IPR Infringement in Internet Sphere
}

ISSN: 2311-8636 (Print)

ISSN: 2312-2021 (Online)

DOI prefix: 10.18034/ajhal

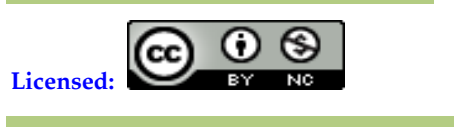

Source of Support: Nil

No Conflict of Interest: Declared

Email for correspondence: mahbublawdu@yahoo.com

\section{Mahbubl Islam}

Lecturer, Department of Law, Eastern University, Danmondi, Dhaka 1205, BANGLADESH

\section{ABSTRACT}

The emergence of the Internet has changed the ways in which we create, distribute, access, and use information. The Internet provides manifold opportunities for users, operators, businesses, and the public at large for speedy, cheap, and global dissemination of information, knowledge, research, and entertainment. At the same time, it also poses complex conceptual and empirical challenges for intellectual property and related rights. Works of intellectual property can be digitized and transferred over the Internet. Many trademarks have been placed on it by the companies for advertising and marketing goods and services. In the field of copyright, a number of works of literature, film and art, and notably computer programs, have been transferred over the Internet. The patent system has also migrated onto the Internet. It is now popular for companies to patent their online business methods. In the Internet Sphere, the infringer can easily misdirect consumers to its website by using another's trademark as a meta-tag, and it is also easy to copy and distribute other's copyright materials unlawfully. Due to global nature of the Internet, an Internet IP infringement usually happens not only within one country but also across borders. All of these have raised many difficulties for the protection of IPRs in Internet sphere. Therefore everyone has been dubious of what the actual laws concerning Intellectual Property rights are in relation to Internet sphere. Today the Internet explosion has made the question of how to enforce IP law on a global scale as an imperative issue. In this Article, the author tries to accentuate the existing as well as changing IPR challenges brought about by the Internet and project what issues a national legislature should consider to meet the demands of the digital revolution. The core object of this study is to scrutinize the compelling factors behind the Intellectual Property Rights Infringements through the Internet and investigate the existing Legal Responses in International, Regional and Local levels. However, the findings demonstrate that mass-awareness, consensus and mutual co-operation among the developed and developing countries, proper enforcement of the existing laws as well as bringing amendments to some areas of Law can be cited as a potential solution.

Key Words: The Internet, Intellectual Property (IP), Intellectual Property Rights (IPR), IPR Infringement, Internet Sphere

\section{INTRODUCTION}

With the tick-tock of the clock the concept of property has been changed. Though the concept of Intellectual Property is not that new but this term is increasingly in use today. On the other hand, while walking with digital revolution in the world we must depend on the Internet. The Internet has brought our communication system in such a position which we 
could not imagine a few decades ago. It has introduced new facilities in all sectors of life as well as considerably benefited the fields of recreation, education and commerce. Besides, it has significantly altered the workplace and opportunities for employment (Grabosky \& Smith, 2001). Thus, to some extent Internet is assisting the world to exploit the creation of Intellectual Properties. At the same time, with its emergence, the world is witnessing some new difficulties in the arena of intellectual Property, the infringement of intellectual property rights (IPR infringement) is the most highlighted one. The advent of the internet has caused policymakers, rights holders, legislators, content creators, content users and others to rethink the way that IP should operate in a modern inter-connected society.

This research aims to mark the ways as well as reasons of IPR infringements over the Internet and to scrutinize the laws relating to combat with such infringements.

Generally, modern technologies make the way of reproduce and counterfeit goods easier, and Internet works as a transit to process these counterfeited or pirated products which constitutes IPR infringement (Dunbar, 2012). For example, films, music files and software are pure digital products and these are frequently copying, sharing and transferring without proper authorization through the internet.

This is the time of globalization and the promises of corporate globalization are to ensure lower product costs and huge market opportunities. As, because of globalization the market of luxury and entertaining products are very wide, the world is now facing with a new surprising threat that is Intellectual Property (IP) theft (Polczynski, 2004).Generally, as the countries individually determine the scope and infringement of IPR protection, the protection for such rights is territorial. However, after the revolution of the internet it has become very easy to digitalize and transfer intellectual property over it. Thus, at present many trademarks, literature, film and art, computer programs are frequently transferring over the internet. Besides, companies are now patenting their online business method very frequently.

As the internet has confirmed to be a vast platform of business and worldwide accessibility, here intellectual properties are more exposed to infringement. Through the Internet the alternative companies or organizations have more opportunities to misguide the consumers by their websites using almost similar trademark as well as using and distributing unauthorized copyright pirated products. Nowadays, due to internet IPR infringement across the border has been easier than ever before. Practically, it is often difficult to take proper action against the original infringer; the IPR holders show a tendency to make the internet server providers responsible for facilitating, containing and distributing protected works or products. However, the Courts find it very difficult to maintain balance between the protection of IPR rights and freedom of information.

In this research, it has been shown that to solve the jurisdictional problem Courts shall consider the private international law issues along with the substantive law issues. Nevertheless, recently the European Court of Justice, in some recent cases, has illuminated the extent of the accountability of the Internet Service Providers in the case of IPR violations and has set out some basic principles relating to this subject (Cases: 'ebay/L'Ore'al July 12th 2011' and 'Scarlet/ Sabam November 24th 2011').

It is evident that protecting IPR in Internet sphere requires new information, knowledge, thinking as well as innovative strategies. As the existing Laws are not $100 \%$ sensational regarding to combat with IPR infringement over the Internet the policy makers should reform the substantive laws as well as bring harmony in private international laws relating to the IP laws connecting to the violation over the Internet. 


\section{Methodology}

The present study is a qualitative legal research. The primary sources like statutes and conventions relating to Intellectual Property law have been communicated. However, the study is mainly based on the secondary sources like commentary books, articles, research works, and documents of WIPO, and different national and international Intellectual property instruments. Critical thinking about the various relevant issues has been frequently relied upon in the study.

\section{Intellectual Property (IP) ANd Intellectual Property Rights (IPR)-}

Intellectual property (IP) indicates to any creative work or invention considered to be the property of its creator. The creative efforts of human brain when resulted in a new creation are known as intellectual property. The inventor of a machine, the author of a book, the composer of music, the director/producer of a film or art work has his special authority and right over his creation as to recompense for the time, money, effort and thought that the owner put into the creation of the work. For this reason, as a rule of natural justice, one should not copy their work or use their work without the inventor's authorization. And he must pay, if required, the author or owner for using his work. This is called Intellectual Property Right.

The objectives of intellectual property protection are mainly as follows:

- To encourage research and inventions

- To induce an inventor to disclose his inventions or discoveries instead of keeping them as a trade-secret.

- To offer a reward for the expenses of developing inventions

- To make products of new invention available to the public by enabling international trade.

\section{Development process in brief}

From beginning, the degree of local or national protection of intellectual property was considered as a vulnerable level for international circumstances. The world first understood the urgency for the protection of intellectual property while in 1873 in Vienna the foreign inventors kept themselves away from exhibiting their invention in the program of "International Exhibition of Invention." The reason they showed is that they were afraid of as their ideas could be stolen and exploited commercially in other countries.

As its consequence, the first major international treaty for the protection of industrial property namely the Paris Convention was adopted in 1883, which covered Patents, Trademarks, Industrial designs, Designs etc. Afterward, in the Berne Convention inserted Copyright as Intellectual Property in 1886.

However, in 1893 these two Conventions was united together to form an international organization called BIRPI. The BIRPI was considered as the predecessor of the World Intellectual Property Organization (WIPO). In 1967 BIRPI became WIPO. And in 1974, WIPO became a specialized agency of the United Nations system of organizations, with a mandate to administer intellectual property matters recognized by the member states of the United Nations. At present, WIPO is operating about 24 treaties (Azam, 2008). Nevertheless, some other International organizations are also conducting projects relating to intellectual property rights protection. After the adoption of TRIPS (1994) in 1996 WIPO entered into a cooperation agreement with the World Trade Organization to control the global trade. 
However, TRIPs has posed all intellectual property rights as trade related rights and has also ended the distinction created by Paris and Berne Conventions on industrial and nonindustrial Intellectual Property rights (Sonderholm, 2010).

\section{Some existing technologies to combat IPR infringement through Digital Technologies} and the Internet

Besides, the Legal Responses there is some popular technology available to thwart IPR infringement through Digital Technology and the Internet. Those are as follows:

- $\quad$ SCMS (Serial Copy Management System)

- Electronic Records

- Encryption

- Digital signature

- Watermarking

- "Access control" methods

- "Rights control" methods

- URL Filtering

\section{IPR INFRINGEMENT IN INTERNET SPHERE}

\section{Internet as a right}

At present, internet is one of the most regular substances with what the largest part of the world is familiar. According to the "INTERNET USAGE STATISTICS-2015", it was found that about 3,366,261,156 people among 7,259,902,243 people of the whole world are connected with the internet (http://www.internetworldstats.com/stats.htm). The line graph is as follows:

Figure 1: Internet Users in the world by Geographic Regions - 2015

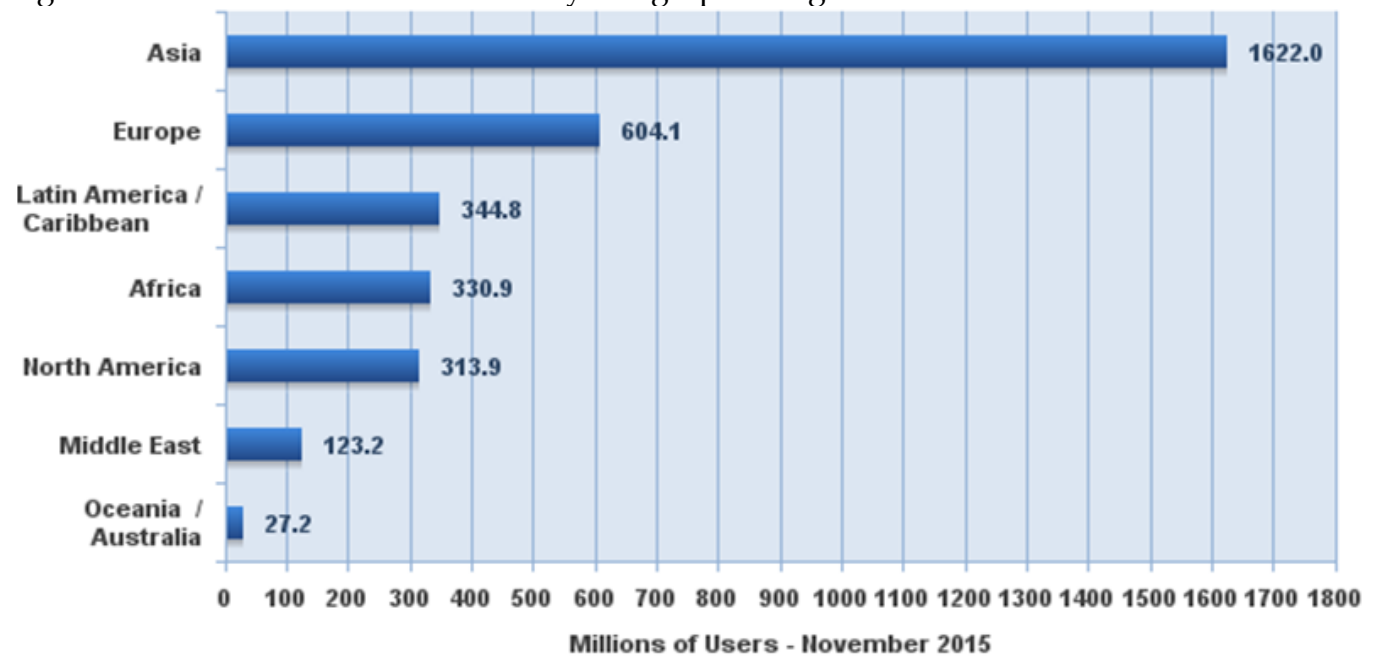

Source: Internet World Stats - www.internetworldstats.com/stats.htm

$3,366,261,156$ Internet users estimated for November 30, 2015

Copyright @ 2016, Miniwatts Marketing Group 
Figure 2: Internet Users in the World by Percentage

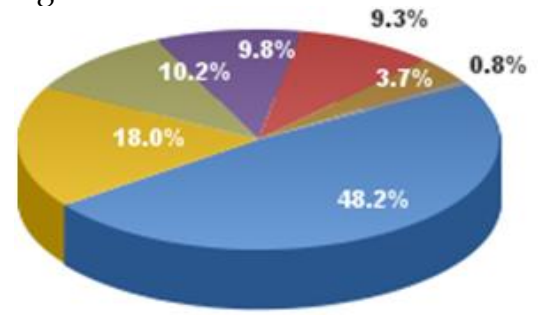

Asia $48.2 \%$

Europe $18.0 \%$

Lat Am / Carib. $10.2 \%$

Africa $9.8 \%$

North America $\mathbf{9 . 3} \%$

Middle East $3.7 \%$

Oceania / Australia $0.8 \%$

Source: Internet World Stats - www.internetworldstats.com/stats.htm

Basis: 3,366,261,156 Internet users on November 30, 2015

Copyright @ 2015, Miniwatts Marketing Group

However, the question is whether the Internet can be considered as a right or whether disconnection from the Internet violates any provision or article of the Universal Declaration of Human Rights. Well, some people argue that the opportunity to access to the Internet is a right. They opine that the Internet can be used to provide essential information about storm warning and crop prices for farmers, or medical services, or legal land records for the farmers in developing countries (Peter, 2002). Cory Doctorow, in his "Homeless People and the internet" expressed as- "You don't need a TV. You don't need a radio. You don't even need a newspaper. But you need the Internet" (Cory Doctorow, 2009). Thus, the Internet is providing valuable information as well as making a platform to express the opinion. And in such approaches, the right to access the Internet covers to Principles of Human Rights as Freedom of Expression and Freedom of information. Article 19 of the UDHR-1948 provides that the right to freedom of opinion and expression includes:

- The right to express, or disseminate, information and ideas;

- The right to seek information and ideas;

- The right to receive information and ideas and

- The right to impart information and ideas through any media and regardless of frontiers.

\section{Trademarks Infringement over Internet}

Trademark can be classified as registered and unregistered. Registered trademark is mainly protected under statutes while the unregistered trademark is protected under the common law principle of passing off (Yang,2010). Registered trademark is protected within the territory in which it is registered and unregistered trademark gets protection when there is a likelihood of consumers' confusion(Yang,2010). However, with the arrival of the internet, the whole situation has been changed. At present, over the Internet trademark is being infringed in several ways:

- Use of another's trademark on a website

- Use of another's trademark as a domain name

- Use of another's trademark as a mega-tag

- Use of another's trademark as a keyword

Use of another's trademark on a website: The trademark law usually makes it possible for divergent business organizations of different jurisdiction to use the same trademark for their same goods or services. Since the internet has a global access, it is very easy to one trader to copy other foreign trader's trademark and place products to the local market (Case, Samsonite Corporation -vs.- Moon Light Travels, 2008., Bangladesh). 
Use of another's trademark as a domain name: Domain names are of two types: as Top Level Domain (TLD) and Second Level Domain (SLD). TLD indicates to the generic description as .com/.net/.bd(which indicates to a country) while the SLD indicates to the trademark or business name: as Nokshi.com. However, as the internet is a worldwide network, it is very easy to use the trademark of another as the domain name. Usually, a domain name indicates to only one address. When the names become almost similar, the problem occurs. In such a case when both the parties feel that they have a legitimate entitlement to the use of the domain name in question because of their company name or trademark. Use of another's trademark as a domain name can also be happened by 'cyber squatting or domain name hijacking' (Waelde, 2000).

Use of another's trademark as a mega-tag: Mega-tag is another issue which has risen with the development of the internet regarding to IPR infringement. A mega-tag is a word that is written on a web page in an electronic language such as HTML. When attached to a web page, the mega-tag is not normally visible to Internet users, but its invisible presence is detected by Internet search engines (Phillips, 2003). Mega-tag determines the relevant topics of a search to a search engine. In the case of mega-tags, dispute arises when the website owners use their competitors' trademarks as mega-tags.

Use of another's trademark as a keyword: Every search engine such as Google, Yahoo, and Bing, etc. maintains a ranking of lists. When any person searches an object or topic through any search engine it suggests some topics categorically. Normally, search engines suggest topics according to the hit list. However, search engines also suggest topics while typing the name of any topic depending on the key words. In such a case, a company can pay the search engine to keep its name at the top of hit list while an internet user will input keywords. While the keywords involve only generic terms, there is no legal dispute as no one has legal rights to these generic terms. However, when the keyword sold is a trademark, infringement claims may be asserted (Sableman, 2001).

\section{Copyright Infringement over the Internet}

The most frequent mode of infringing IPR over the Internet is the infringement of Copyrights. There are several reasons behind it. First of all, the ability of rapid reproduction and distribution of the internet can be traced as a compelling reason. Secondly, much copyright material published on the internet has been made available free of charge. Thirdly, it is difficult to identify an individual internet user. Users may, therefore, infringe copyright with little risk of detection, especially if the infringements are relatively small-scale and non-persistent (Lindsay, 2000).

Taking the above-mentioned matters into concern the way of copyright infringement can be listed as follows:

- $\quad$ Linking and framing

- Uploading copyrighted material

- Downloading copyrighted material

Linking and framing: One of the most fabulous features of the Internet is its linking ability. Linking is of two types: hypertext linking and inline linking. A hypertext reference link appears onscreen as a highlighted citation or phrase that is differentiated from a regular text by a special color or format such as underlining. 
When an internet user activates the link by clinking on the highlighted text, the web browser software retrieves the corresponding document from the external site and creates a copy, which is then displayed on the screen (Chan, 1999) . On the other hand, an inline link allows a website designer to inline a graphical image from an external site and integrates it as part of the local onscreen display. For example, if an external site contains a photograph, it can be in-lined into the local website and shown as part of the current display. The URL does not change, and the user may not realize that the linked image actually comes from somewhere other than the linked site (Chan, 1999).

However, framing is another type of dynamic connection that is similar to inline linking. It allows a website designer to merge or pull in an entire external site, or portions thereof, and surround it with frames of his creation. The upshot, as with inline linking, is that the external site seems to be part of the local site and the URL remains unchanged. The hazard of each of these types of linking is that Internet users will conceive that the linked sites are inter-connected.

Uploading copyrighted material: Another very frequent mode of copyright infringement over the internet is uploading documents or materials which are copyrighted. It is very common that many copyrighted materials are available on the internet. Most of the users assume or many ignore the fact that these materials are technically restricted. However, they assume that a material is available electronically entitles them to upload it to their websites (Reed, 2004).

The jurisdictional problem is very common as well as major in such case of infringement. In the internet sphere, where data moves in a widely diffused fashion, copyright-protected works can be globally exploited. It is quite possible that an uploading dispute has a connection with several different countries. For example, there may be a dispute that a person, who resides in Bangladesh, has uploaded a company's English copyrighted material onto the BBS operated by him based in France, without the company's permission. As this dispute has a connection with three countries, which country's court should have jurisdiction? Moreover, if the company owns the copyrights in twenty or thirty different countries, all of his copyrights will be infringed simultaneously due to the global access of the BBS. In such a situation, many countries will have connections with the dispute. The courts of all these countries may fight over the jurisdiction.

In the above case, as the dispute has a connection with the Bangladesh, UK, and France, the forum court will determine what law should apply after deciding to take jurisdiction. If BD or UK law has been chosen, fair dealing will apply, but if French law applies, the defendant cannot be protected by fair use or fair dealing. It is not sure if the court will give the same judgment by applying exceptions to copyright provided by the French law.

Downloading copyrighted material: Downloading copyright material is the subsequent step of uploading copyright materials. Once the unauthorized copyright materials have been uploaded and remained available, the next possible thing is that internet users will download it from the internet. The copyright owners are reluctant to bring actions against millions of individual infringers. Much attention has been paid to the possibility of holding liable those parties who provide the equipments or the facilities used for infringing activities (Lloyed, 2008). 


\section{Patent Infringement}

In promoting the development of the intrinsic technical infrastructure for the Internet the patent system has played a vital role. This infrastructure established through patent protection has provided a large market for new ideas, innovations and technological inventions. However, the new technologies cause challenges to the conventional legal scheme for the patent system. Among them, business methods patents and software patents are particularly under threat due to the emergence of the internet.

On the internet, some patents have recently been granted to certain inventions concerning business methods. In the case of Amazon.com v. Barnesandnoble.com, Inc (1999) the internet bookseller Amazon sued its rival Barnesandnoble, alleging infringement of its one-click ordering patent in the US District Court for the Western District of Washington. Amazon's patent was directed to a 'one-click' method and system for motion for preliminary injunction. However, in appeal the case was settled between the parties.

In the past, software was often sold as an integral part of the computer system, but now software products are often marketed in the form of computer readable media, for example, diskettes and CD-ROMs or directly over the internet. Software-related inventions are thus stored in such media, and commercialized separately from the computer hardware.

\section{LEGAL RESPONSES TO IPR INFRINGEMENT ON THE INTERNET}

The enhanced ability to copy and distribute information triggered by the Internet has provoked a technological response. In order to gain back control, right holders have made use of so-called technological protection measures (TPM) - including, for instance, Digital Rights Management (DRM) schemes - that are aimed at regulating the copying, distribution, and use of and access to digital works through code ("code is law") (Gasser, 2006). Activists, in turn, have immediately taken counter-measures and designed tools that enable the hacking of technological protection measures such as copy and access controls (Gasser, 2006). Legal responses regarding to protect IPR infringements form internet or digital revolution are as follows:

\section{International Frameworks}

The Berne Convention: In 1886, the first attempt to balance copyright law internationally was taken by the Berne Convention. The convention established a minimum level of copyright protection for the member nations to follow and adopted the "national treatment policy". The treaty also established that the International Court of Justice in The Hague would exercise jurisdiction over disputes between member nations, but the Treaty left nations free to declare their immunity from the jurisdiction, and many states have done so. Indeed, The Hague Court has never presided over a treaty compliance dispute to date.

Measures to accommodate new technological and digital development: To accommodate new social and technological developments, the Berne Convention was updated quite regularly as:

- The Act of Berlin (13 November 1908);

- The Additional Protocol of Berne (20 March 1914);

- $\quad$ The Act of Rome (2 June 1928);

- $\quad$ The Act of Brussels (26 June 1948);

- The Act of Stockholm (14 July 1967) along with the Protocol Regarding Developing Countries;

- And, finally the Act of Paris (24 July 1971), along with an Appendix regarding developing countries. 
After the 1971 Paris Act, the international community for a while adhered to the strategy of "guided development" to respond to changing technology, rather than trying to establish new international norms. WIPO bodies (in the beginning often in cooperation with UNESCO) developed recommendations, guiding principles and model provisions aiming to assist governments in responding to new technologies. These recommendations mostly interpreted existing international norms, but they also included new standards.

The TRIPs Agreement: As copyright was becoming increasingly significant in shaping international trade with the emergence of the internet, the 1994 Uruguay Round of GATT produced TRIPs- the Agreement on Trade-Related Aspects of Intellectual Property Rights. Regarding copyrights, the Agreement did not introduce any radical changes to the Berne System but rather based member obligations on the substantive provisions (Articles 1 to 21) of the Berne Convention (except the provisions on moral rights). Rather, the Agreement explained and clarified existing copyrighted principles and focused on enforcement.

Besides, the TRIPs first made it clear that databases and computer programs fall under the definition of copyrightable works under the Berne Convention. Moreover, it calculated the term of protection in certain cases and clarified limitations and expectations.

The WIPO Copyright Treaty (WCT): Because of the digital revolution, to combat with the frequent rate of piracy it became evident that guidelines provided by the WIPO need some amendments. The internet's truly spectacular expansion raised a variety of unexpected challenges to the copyright regime, requiring a global response. Therefore, WIPO initiated work on development of new binding norms to account for the advent of digital networks. However, these processes resulted in two new documents, which are sometimes referred to as the "Internet Treaties":

- $\quad$ The WIPO Copyright Treaty (WCT)

- $\quad$ The WIPO Performances and Phonograms Treaty (WPPT)

The WCT adapts it to the digital environment, rather than overriding it or creating an independent framework. It requires that member states guarantee authors' protection with on distribution, commercial rental, and communication to the public and making available to the public of their works online. Explicit protection is provided for computer programs and databases. Along with adapting old concepts to the internet environment, the WCT introduced two major new concepts, imposing on national legislatures and obligation to provide liability for (a) circumvention of technological protection measures and (b) tampering with rights management information.

The WIPO performance and phonograms Treaty (WPPT): The WPPT can also be called as rights related to sound recordings and performances. It updates the Rome Convention of 1961 and aims at protecting the interests of performing artists (singers, musicians, etc.) and producers of Phonograms. The WPPT ensures that these stakeholders have exclusive rights of reproduction, distribution, commercial rental and the online "making available" to the public of their performance or recordings. Just like WIPO Copyright Treaty, the WPPT contains obligations concerning technological measures, rights management information and enforcement.

\section{Selected Regional and National Legal Frameworks}

Internet Treaty in U.S.A- the Digital Millennium Copyright Act (DMCA): In October 1998, to implement the rules and laws of WCT and WPPT regarding to the copyright infringement over internet, the United States adopted another Copyright Act locally 
named the Digital Millennium Copyright Act (DMCA). This Act moved the nation's copyright law into a Digital age. Main features of this Act are:

- Declares the avoidance of anti-piracy measures as a crime.

- Outlaws the manufacture, sale, or distribution of code-cracking devices used to illegally copy software.

- Protects internet service providers from copyright infringement liability for simply transmitting information

- Limits the liabilities of nonprofit institutions of higher education.

- $\quad$ Requires that the webcasters pay licensing fees to record companies.

Internet Treaty in Europe: The Information Society Directive and other Directives: In Europe "Information Society Directive" sets out the basic frameworks in implementing the WIPO prescribed rules regarding to the infringement over internet. It was adopted on June 22 of 2001. The directives generally apply to:

- The legal protection of computer programs

- The rental right

- The lending right

- Certain rights related to copyright in the field of intellectual property, copyright and related rights applicable to broadcasting of programs by satellite and cable retransmission

- The term of protection of copyright and certain related rights

- The legal protection of databases.

None of the existing international instruments is by any means a comprehensive response to the IPR infringement challenges associated with the Internet revolution. Much of the process of defining policy solutions is left to national policymakers themselves. However, the above mentioned treaties present a solid framework for national efforts to address the most urgent issues.

Asia Pacific Economic Co-operation: Introduced enforcement system to curtail onlinepiracy and fully implements the provisions of TRIPs agreement.

African Regional Intellectual Property Organization (APRPO): This organization has 17 member states. It promotes the exchange of ideas \& experiences, research \& studies relating to industrial property matters and Protects infringements.

Organization of African de la propriete Intellectuelle (OAIP): This organization encourages creativity and technology transfer through the use of industrial property systems and protects Digital Intellectual Properties.

The Internet Society (1992): It's a non-profit organization which suggests the use of the internet for the benefit of people throughout the world. It supports protection of Digital Intellectual Properties and provides friendly guideline.

France: Loi favorisant la diffusion et la protection de la cre ation sur Internet, 2009: This Act highlighted the issue of appropriateness of suspension of internet access as a remedy for the copyright infringement.

New Zealand: The NZ Copyright (Infringing File Sharing) Amendment Bill, 2010: This amendment bill brings the copyright infringement matter over the internet under legislative frameworks in New Zealand. 
CHINA: Copyright Act Amendment: China first introduced amendments to its Copyright Act on 13 may 2009 which provides an ISP with Protection against liability with certain conditions.

Bangladesh: legal responses in brief: The current basic laws relating to Intellectual Property Rights in Bangladesh are as follows:

- $\quad$ Patents and Designs Act, 1911.

- Copyright Act, 2000.

- Trade Marks Act, 2009.

The development of the IP system depends on the effective enforceability of IP rights. The Government of Bangladesh has enacted the new law, The Trademarks Act, 2009 giving the scope to protect the services under International Classes (34-45). The said Act has a clause (109) authorizing the customs officials to call for records and disclose the source of importing items prohibited under the Customs Act, 1969, Section 15(d)(e) \& (f).

\section{FINDINGS}

One of the basic purposes of this study was to find out the reasons of Intellectual Property Rights infringement over the internet as well as to hit upon the question whether the existing legal responses are good enough to combat with the IPR infringement by digital technologies. The findings this study is as follows:

- The tempo of the digital technology development is much swifter than the Intellectual Property laws.

- The flourished and commercial achievements of the Intellectual Properties are largely depended on the Internet. However, the internet serves some negative aspects on the IP rights protection.

- The Tendency of IPR infringement through the Internet is relatively higher in developing countries. This is because either they do not have adequate resources or the IP rights enforcement laws and authorities are very flexible in those countries.

- There is an apparent jurisdictional problem regarding the IPR infringement over the internet. The lack of International Intellectual Property Legal Framework to solve the jurisdictional problem can be traced as its compelling reason.

- Though there are some International Legal Frameworks to combat the IPR infringement in internet sphere, it is yet to start the practice of empirical application of these frameworks.

- Delays in resolution of Patent and Trademark applications are another ground of IPR infringement over internet. This is because the Digital Technology takes less than a minute to steal or copy an idea.

\section{Possible Way OUt}

To combat with the IPR infringement over the Internet simply two options can be focused: Sticking with the existing laws and bring some new Laws to tackle IPR infringements in Internet sphere. However, the data and the results of the analysis indicate that some specific and pragmatic amendments are very essential in this regard. Since everyday new ideas are introducing in Internet arena, the enforcement policy of the Intellectual Property Rights should be handled with more scientifically and empirically. Besides, Jurisdictional matters should be more clarified in the international frameworks. The possible way out is given below: 
- Introducing a new jurisdiction for cyberspace cases as there is no territorial boundary. Massages can be transmitted from any physical location to any other location without any physical barrier. Based on this, some scholars have advocated that cyberspace should have its own jurisdictional entity (Yang, 2010).

- Adopting special jurisdictional rules for Internet IP infringement cases can be another potential solution. The court should give the power to exercise jurisdiction in four places, they are:

$\circ \quad$ The place of uploading the infringing material

- The place of downloading the infringing material

- The place where the host server is situated

- The place of the defendant's or the claimant's habitual residence

- $\quad$ Reducing the delays in resolution of Patent and Trademark applications. This removes the option to exploit the system by delaying the process.

- In order to maintain the balance of interest between the IPR holders and the users, national framework should be made more flexible. In such case the principles of international legislation must be protected.

- The internet Jurisdiction could be regulated by assembling jurisdiction into a coherent, codified regime. Under this approach, representatives from all the countries would participate in the process of drafting in different countries. These regulations would be reviewed and ratified by all the countries and the parties would agree to insert the regulation into their legal code. This would solve the following problems:

- Internet Jurisdiction would not conflict with the domestic law

- The courts in one country will not have the discretion to apply their jurisdictional rules in an internet dispute

- Internet users will be aware of the laws governing them and adjust their activities accordingly.

- The moral conflict between the developed and developing countries in enforcing the IP laws should be taken into an end through open discussion. The developed countries should provide more technological and financial support to the developing countries so that they can combat with compelling forces of IPR infringement.

- Finally, creating public awareness is inevitable. The moral condition of the infringers should be changed. People should make it realize that infringing IP is not a creativity but amounts to theft.

\section{CONCLUSION}

Protecting Intellectual Properties is the brain-child of the developed countries while less developed countries are showing less interest in favor of it. The developed countries argue that it is inevitable for encouraging new inventions, ideas and researches as well as to provide some financial benefits to the inventor. However, this idea of protecting Intellectual Properties is not new. The world society had its own mechanism from very long past. Nonetheless, the existence and proper functioning of these mechanisms faced a new inevitable threat with the emergence of the Internet.

The emergence of the internet has both positive and negative effects for the IP rights. The commercial success and transactions of newly invented products or ideas are now mostly dependent on the Digital Technology and the Internet. Besides, it puts risk to infringements as well. It seems that the infringement through the Internet is more frequent and safer. Though national, regional and international legislations are in force banning the 
dissemination of circumvention tools; it has become implausible to protect the IP rights in the Internet Environment. Everyday new technologies and techniques are introducing in the Internet Sphere. Therefore, the universe should walk towards a new morning. It is the reality that driving by necessity people will continue introducing new ideas and inventions. Thus, based on the Internet, some will find new passage to copy or use another's idea or invention for his own benefit. All we can do is to codify the laws relating to IPR protection and set a universal standard of jurisdiction for the Internet IP violation cases. And, in my opinion, this will help the Internet IP infringement cases to stop knocking for shelter as a little lost child do.

\section{REFERENCES}

Azam, M. M. (2008), Intellectual Property WTO and Bangladesh, (ed-2008), New Warsi Book Corporation, Page-7

Chan, R. (1999), Internet Framing: Complement or Hijack? 5 Mich Telecomm, Tech. L Rev 143 at 146]

Dunbar, T. (2012), combating Online Trademark and Copyright Infringement: ICE and DOJ domain name seizures new tools in the government's efforts to combat online IP infringement

Gasser, Urs (2006), Legal Frameworks and Technological Protection of Digital Content: Moving Forward towards a Best Practice Model.

Grabosky \& Smith (2001), Electronic Theft: Unlawful Acquisition in Cyberspace. Cambridge University Press

Lloyed, L.J. (2008) Information Technology Law, Oxford University Press, 5th ed. p401

Narayan, P. (2009) Intellectual Property Law, Eastern Law House, 3rd ed.

Peter K. Yu (2002), Bridging the Digital Divide: Equality in the Information Age

Phillips, J. (2003) Trademark Law- A Practical Anatomy, Oxford University Press at p593

Polczynski, Dr. Mark H., (2004) Protecting Intellectual Property in a Global Environment, pp 83-95.

Reed, C. (2004) Internet Law: Text and Materials, Cambridge University Press, $2^{\text {nd }}$ ed. p 101.

Sableman, M. (2001), Link Law Revisited: Internet Linking Law at Five years", Berkeley Technology Law Journal, Vol.16, 1273, at 1309]

Singh, M. K., 2011, Is "three strikes and you're out" an appropriate measure for online copyright infringement, Tilburg University, pp. 40, $1^{\text {st }}$ Para.

Waelde, C. (2000), Trade Marks and Domain Names: There "s a lot in a namee in law and the InternetA Framework for Electronic Commerce (Edwards, L. and Waelde, C., (ed), Hart Publishing, 2nd ed. At pp133-136

Yang, F. (2010), Infringement of Intellectual Property Rights Over the Internet and Private International Law. Page.11 
Publish Online and Print Version Both

Online ISSN: 2312-2021

Google Scholar: https://goo.gl/eozEWi 